\title{
Perancangan Sistem Informasi Pemasaran Sepatu Online Dalam Menumbuhkan Pasar Global
}

\author{
Design Of Online Marketing Information System of Shoes For Global Market \\ Enhancement \\ Sandy Kosasi \\ STMIK Pontianak; Jl. Merdeka No. 372 Pontianak, 0561-735555 \\ Jurusan Sistem Informasi, STMIK Pontianak, Pontianak \\ e-mail: sandykosasi@yahoo.co.id
}

\begin{abstract}
Abstrak
Sistem Informasi Pemasaran Sepatu Online merupakan sebuah representasi model bisnis baru melalui penerapan teknologi informasi. Kesempatan membangun mitra bisnis bersama tanpa harus bergantung kepada skala usaha bisnis sebelumnya. Memberikan jaminan personalisasi kepada pelanggan secara intensif dan interaktif sehingga dapat meningkatkan nilai-nilai kepuasan pelanggan melalui sistem layanan teknologi pemasaran secara digital. Bahkan dapat ikut serta dalam menumbuhkan usaha kecil dan menengah secara nasional.Tujuan penelitian menghasilkan prototipe perangkat lunak untuk mengelola dan menjalankan bisnis pemasaran sepatu online agar masyarakat mudah memenuhi segala kebutuhan, memperluas sasaran pangsa pasar untuk menumbuhkan berbagai peluang bisnis dalam pemasaran global. Perancangan sistem ini mengunakan model situs dengan tahapan spesifikasi pembuatan melalui studi kelayakan, mengidentifikasi kebutuhan pengguna tentang kepuasan penggunaan aplikasi dalam pembuatan dan observasi sistem berjalan dan validasi kebutuhan. Sistem ini memiliki fitur navigasi dengan kemudahan bagi pengunjung dalam menelusuri situs web dalam pencarian dan pemesanan produk. Kesempatan membangun hubungan yang lebih personal dengan pengunjung agar dapat mempertahankan dan membangun loyalitas pelanggan secara berkelanjutan.
\end{abstract}

Kata kunci - Sistem Informasi Pemasaran, Sepatu Online, Pasar Global, Loyalitas Pelanggan

\begin{abstract}
Online marketing information system of shoes is the representation of a new business model through the implementation of information technology. It provides the opportunities to build the business relationships without depending on the scales of previous business and gives the guarantee of personalisation to the customers intensively and interactively. Therefore, it can improve the values of customers' satisfaction through the service system of marketing technology digitally. Online business can even improve small and medium enterprises nationally. This research aimed to produce the prototype of software used to manage and run the online marketing of shoes. Therefore, customers' needs are easily fulfilled and market shares are expanded to improve various business opportunities of global marketing. The design of this system uses a site model involving these stages: design specification through feasibility studies, identification of customers' needs on the uses of the application, running system observation, and validation of needs. This system has a navigation feature providing easiness to visitors to search and order the products, and opportunities to build a more personal relationship with the visitors and continuous customers' loyalty.
\end{abstract}

Keywords-Marketing Information System, Online Shoes, Global Markets, Customers' Loyalty 


\section{PENDAHULUAN}

Keberadaan bisnis offline sudah mulai memperlihatkan penurunan yang cukup drastis dengan kondisi perekonomian saat ini. Kebutuhan modal usaha dan investasi semakin meningkat. Nilai pengembalian tidak sebanding dengan investasi modal usaha. Kejadian pemutusan hubungan kerja karyawan. Ketersediaan bahan material tidak lagi mencukupi kebutuhan. Meningkatnya jumlah beban hutang usaha. Daya beli dan nilai tukar rupiah semakin menurun dan hilangnya pengaruh insentif pasar. Semua kejadian ini membutuhkan proses rekonsiliasi bisnis agar dapat segera kembali normal. Upaya melakukan proses rekonsiliasi bisnis dapat melalui sistem informasi pemasaran online [1]. Sistem ini merupakan sebuah representasi model bisnis baru, yang dapat memberikan kemudahan kepada konsumen atau pelanggan melakukan transaksi dengan jangkauan pemasaran yang lebih luas dalam meningkatkan pemasaran secara global, kesempatan membangun mitra bisnis bersama tanpa harus bergantung kepada skala usaha bisnis, tidak membutuhkan investasi dan biaya operasional besar dengan jumlah karyawan yang banyak, dapat ikut serta dalam menumbuhkan usaha kecil dan menengah secara nasional [2]. Selain itu juga dapat membangun hubungan personalisasi dengan pelanggan sehingga menjadi lebih dekat, komunikatif dan menjadikan pelayanan dapat lebih interaktif [3].

Sistem informasi pemasaran online memiliki elemen daya saing yang sangat signifikan karena mudah menyesuaikan dengan kondisi pasar sasaran. Mudah menjalin kerjasama dengan mitra bisnis dalam pengadaan dan mendistribusikan produk dan jasa secara langsung tanpa perantara. Kenyataan ini jelas akan menurunkan biaya operasional dan meningkatkan marjin usaha [4]. Kondisi ini merupakan faktor penting bagi setiap lapisan masyarakat untuk ikut serta menawarkan produk dan jasa melalui kepemilikan usaha bisnis pemasaran online [5]. Cukup dengan mengupload informasi berupa foto atau informasi tentang produk dan jasanya. Sifatnya yang dinamis memberi kemudahan melakukan sistem pemeliharaan dan tanggap membangun hubungan loyalitas pelanggan saat ini dan mendatang [6].

Keberhasilan bisnis pemasaran online sangat bergantung kepada kesiapan teknologi aplikasi media sosialnya [7] dan menumbuhkan sifat komunikasi interaktif melalui jejaring media sosial [8]. Kondisi ini penting mengingat dalam memenuhi kebutuhan produk dan jasa tidak lagi hanya fokus kepada kualitas namun lebih kepada nilai-nilai estetika dari produk dan jasa. Media sosial telah mengubah cara dan perilaku manusia berkomunikasi, berkolaborasi, mengkonsumsi, dan menciptakan nilai-nilai [9]. Memiliki kemampuan membangun hubungan dan membina interaksi secara personal.

Meningkatkan komunikasi dalam dan di luar organisasi melalui kolaborasi pengetahuan untuk mencapai dan meningkatkan aksesibilitas informasi. Konsumen memiliki keleluwasan membuat pilihan sebelum melakukan transaksi jual beli secara online melalui komunikasi dua arah. Keinginan berpartisipasi, berinteraksi, dan menciptakan nilai bagi konsumen membuat media sosial semakin menjadi pertimbangan utama dalam merumuskan aktivitas dan menjalankan bisnis pemasaran online. Pernyataan ini didukung oleh McKinsey [10], dimana hasil risetnya memperlihatkan banyak perusahaan berhasil memperoleh keuntungan dan meningkatkan kinerja bisnisnya melalui teknologi media sosial.

Penelitian sebelumnya yang relevan mengenai penerapan bisnis pemasaran online merupakan model bisnis yang paling umum dari aplikasi perniagaan elektronik. 
Memiliki kerangka kerja dan fungsi secara komprehensif dalam bentuk arsitektur fungsional dan tujuan sistem toko online untuk mendekatkan dengan pelanggan [11].

Pembuatan bisnis pemasaran online memiliki efek kepada keputusan pembelian konsumen. Memiliki dukungan transaksional dapat menarik pelanggan tradisional dengan beragam kemudahan untuk memelihara loyalitas pelanggan [12]. Meskipun bisnis pemasaran online telah menjadi saluran bisnis online di negara-negara maju.

Namun untuk negara berkembang masih berada pada tahap inovasi dan merupakan peluang bisnis yang sangat menjanjikan [13]. Pelanggan melakukan transaksi pada bisnis pemasaran online lebih mementingkan kepada kepercayaan daripada harga, baik untuk pelanggan yang berulang dan pelanggan potensial. Hubungan personalisasi dengan pelanggan menjadi bagian penting dalam meningkatkan dan memperluas pangsa pasar [14].

Keberadaan bisnis pemasaran online dapat memberikan jaminan personalisasi kepada pelanggan secara lebih intensif dan interaktif sehingga dapat meningkatkan nilai-nilai kepuasan pelanggan. Sejumlah penelitian memperlihatkan bahwa bisnis pemasaran online memiliki tingkat kompetensi yang tinggi dan handal dalam membangun hubungan yang loyal dengan pelanggan. Kelancaran dan kemudahan mekanisme melakukan transaksi bisnis pemasaran online memberikan kesempatan menumbuhkan sasaran pasar global [15]. Sistem pemasaran online melalui media sosial telah mengubah struktur kekuasaan di pasar dan sebagai strategi mengakumulasi kebutuhan pelanggan dan intelijen pasar sebagai saluran pemasaran langsung [16].

Penelitian ini menitikberatkan menghasilkan sebuah prototipe perangkat lunak sistem informasi pemasaran untuk membantu masyarakat yang memiliki usaha kecil dan menengah dalam memasarkan produknya keluar dari daerah bahkan diharapkan dapat menjadi sumbangan devisa bagi pertumbuhan daerah Kota Pontianak dan sekitarnya. Jadi tidak hanya fokus kepada sistem onlinenya atau penggunaan media sosial saja.

Namun lebih kepada membangun sebuah platform online yang dapat memasarkan produk sepatu khas dari masyarakat setempat. Melalui prototipe perangkat lunak ini membangun pasar secara online sehingga proses transaksi menjadi lebih cepat, mudah dan transparan. Hasil penelitian ini sesuai dengan tujuan penelitian menghasilkan sebuah prototipe perangkat lunak sistem informasi pemasaran online bagi usaha kecil dan menengah. Melalui sistem ini dapat mengelola dan menjalankan bisnis pemasaran sepatu online agar masyarakat yang menjalankan industri usaha kecil dan menengah dapat dengan mudah memasarkan hasil produksi sepatunya, memenuhi kebutuhan pelanggan secara personal, memperluas sasaran pangsa pasar dan menumbuhkan berbagai peluang bisnis dalam pemasaran global.

\section{METODE PENELITIAN}

Penelitian ini berbentuk survei dengan pendekatan kebutuhan perluasan pasarnya menggunakan analisis kesempatan pasar sasaran, pembuatan model bisnis, antarmuka pelanggan, komunikasi pasar dan rancangan prototipe [17]. Metode dalam penelitian ini menggunakan R\&D (Research and Development). Instrumen penelitian dengan teknik wawancara, observasi dan sebaran angket pertanyaan. Populasi dalam penelitian ini adalah semua industri usaha kecil dan menengah yang menjalankan bisnis pemasaran sepatu. Untuk pengambilan sampel sebanyak 30 usaha kecil dan menengah yang menghasilkan dan memasarkan produk sepatu di Kota Pontianak dengan teknik 
purposive sampling. Pengumpulan data penelitian berasal dari data primer dan sekunder.

Untuk data primer berasal dari hasil survei kepada sejumlah responden terpilih dengan komposisi pimpinan, manajer, dan staf administrasi. Instrumen penelitian menggunakan daftar angket dengan menggunakan skala Guttman dengan unit analisis organisasi [18]. Semua jawaban ini akan dirata-ratakan dan mewakili masing-masing unit organisasi usaha kecil dan menengah. Sementara data sekunder berasal dari laporan-laporan hasil kegiatan setiap usaha kecil dan menengah yang memasarkan produk sepatu. Perolehan data penelitian ini penting untuk mengetahui kebutuhan spesifik dari setiap unit industri tersebut agar menjadi landasan dalam menghasilkan prototipe perangkat lunak tersebut.

Untuk prototipe perancangan sistem informasi pemasaran sepatu online menggunakan model situs dengan tahapan, yang diawali dengan menentukan spesifikasi pembuatan melalui studi kelayakan, mengidentifikasi kebutuhan pengguna tentang kepuasan penggunaan aplikasi dalam pembuatan dan observasi sistem berjalan serta melakukan validasi kebutuhan dari setiap usaha kecil dan menengah produksi sepatu. Perancangan perangkat lunak menggunakan bahasa pemrograman dengan pengkodean HTML, PHP, CSS, jQuery, dan dengan alat bantu Dreamweaver CS5.Menggunakan XAMPP 1.8.0-VC9 untuk menjalankan Apache web server dan PhpMyAdmin sebagai database server.Selanjutnya untuk perancangan sistem perangkat lunaknya menggunakan metode prototype (Gambar 1), dengan tahapan awal melakukan perencanaan syarat-syarat kebutuhan sistem; kedua, melibatkan pengguna untuk merancang sistem dan menerapkan sistem; dan terakhir tahap implementasi. [19].

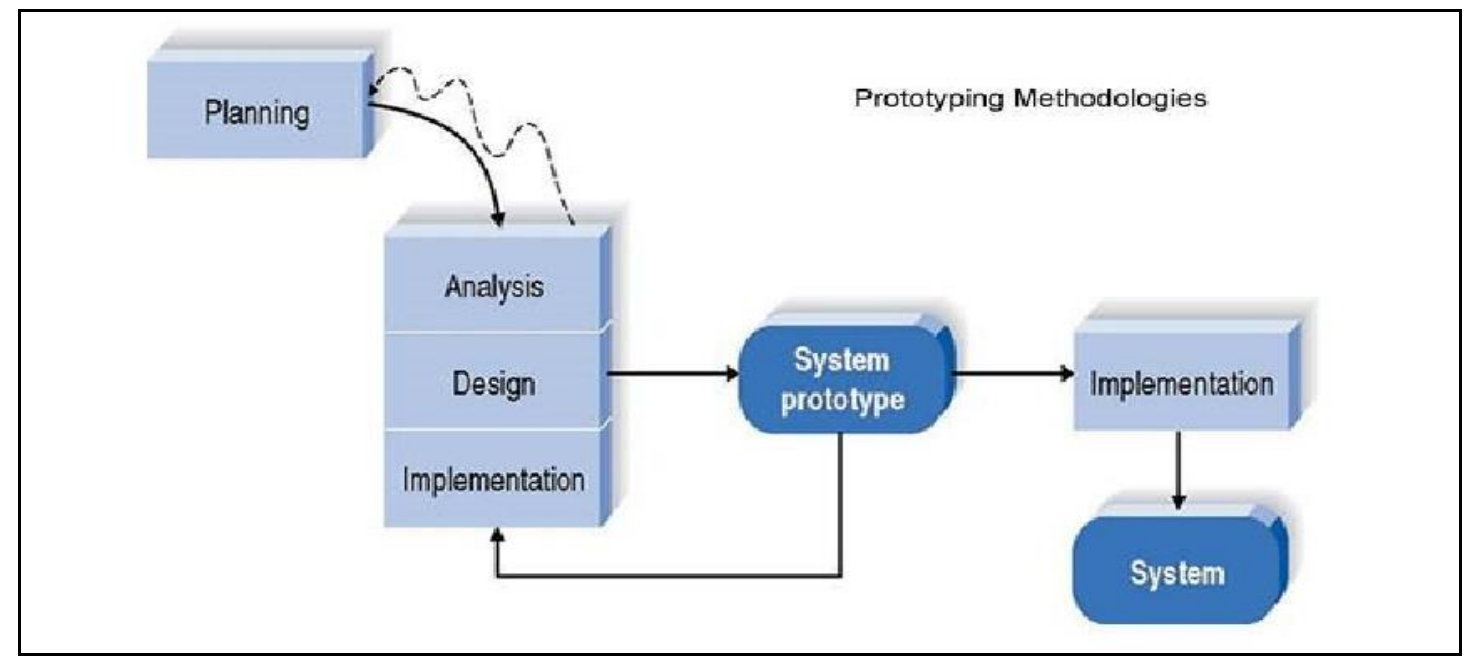

Gambar 1. Metode Perancangan Prototipe

\section{HASIL DAN PEMBAHASAN}

Dalam penelitian ini membahas mengenai perancangan sistem informasi pemasaran bisnis online dengan menggunakan objek sepatu. Untuk kebutuhan objek sepatu ini diawali dengan mengumpulkan semua persyaratan kebutuhan dalam rangka mempromosikan beragam model, tipe dan harga sepatu. Merancang struktur navigasi, modul-modul sistem dan subsistem dalam kaitannya dengan konsistensi kebutuhan 
beranda pada situs pemasaran bisnis sepatu online. Sistem informasi pemasaran sepatu online memiliki 2 (dua) struktur jenis kebutuhan: kebutuhan fungsional dan kebutuhan nonfungsional.

Kebutuhan fungsional adalah kebutuhan yang mengelola semua proses bisnis sistem pemasaran online. Sementara kebutuhan nonfungsional menitikberatkan kepada properti perilaku sistem. Untuk perencanaan kebutuhan sistem meliputi semua struktur informasi dan elemen-elemen semua pengetahuan dari setiap pelanggan.

Mengidentifikasi kebutuhan informasi dan batasan sistem sebagai alternatif proses melakukan sinkronisasi, konvergensi dan interoperabilitas informasi agar lancar dalam mengelola semua pengetahuan pelanggan perusahaan. Sistem yang dibangun adalah bersifat umum untuk semua industri usaha kecil dan menengah agar dapat menunjang semua aktivitas dalam memasarkan produk sepatu secara online. Untuk itu mekanisme dan proses dari setiap fungsi sistem online ini berlandaskan kepada kebutuhan perilaku dari pengguna.

Orientasi dalam fase pembuatan adalah menyelesaikan masalah-masalah perusahaan dalam menjual dan memasarkan produk dan jasa mereka. Meskipun teknologi informasi dan sistem bisa mengarahkan sebagian dari sistem yang diajukan, fokusnya akan selalu tetap pada upaya pencapaian tujuan-tujuan perusahaan. Proses pembuatan sistem harus dapat mencari dan menelusuri segala informasi yang signifikan untuk memenuhi kebutuhan aplikasi yang dibangun. Perancangan sistem informasi pemasaran bisnis online menggunakan arsitektur sistem informasi dalam bentuk strategi back-end dan front-end. Dimana back-end merupakan halaman yang di khususkan bagi administrator untuk kebutuhan mengelola mekanisme dan proses bisnis sistem pemasaran online. Sementara untuk halaman front-end lebih disediakan untuk kebutuhan pengguna akhir, yang dalam hal ini adalah pelanggan atau konsumen potensial, baik yang hanya sekedar ingin melihat informasi maupun bagi para konsumen atau pelanggan yang memiliki minat melakukan proses transaksi bisnis sepatu secara online.

Deskripsi kebutuhan fungsional terdiri atas kebutuhan konsumen, manajemen perusahaan, administrator sistem informasi pemasaran sepatu online, dan sejumlah fitur sistem agar mendapatkan kenyamanan dalam melakukan transaksi bisnis pemasaran sepatu online. Modul kebutuhan konsumen memiliki halaman khusus untuk keanggotaan dalam mengelola pesanan dan permintaan produk. Kemudahan menelusuri dan mencari produk dan jasa yang menjadi kebutuhan secara mendetil. Memiliki form untuk proses transaksi bisnis pemasaran produk sepatu secara online, fitur form konsultasi secara online, dan fitur form konfirmasi proses pembayaran pemesanan produk dan validasi via SMS sehingga keakuratannya menjadi lebih terjamin keamanannya.

Berikutnya, kebutuhan manajemen perusahaan memiliki sejumlah fitur, diantaranya kemampuan menampilkan informasi semua produk secara lengkap termasuk harga produknya, menyediakan form konfirmasi pemesanan, form untuk melakukan interaksi dan komunikasi dengan pelanggan, dan tersedianya form untuk melakukan promosi produk. Selanjutnya untuk modul administrator berkaitan dengan fungsi mengelola sistem pemasaran sepatu online. Fungsi dari modul ini memiliki fitur pendataan produk, informasi pengetahuan konsumen dan pelanggan, kelompok kategori dan jenis produk, melakukan pemrosesan transaksi dan pengiriman produk, melakukan validasi untuk semua penerimaan pembayaran, mengelola sejumlah transaksi sebagai kebutuhan informasi bagi manajemen. Selanjutnya untuk kebutuhan non-fungsional 
terdiri atas infrastruktur internet, registrasi nama domain, web hosting, pengembangan web, pengadaan perangkat keras dan perangkat lunak. Untuk persyaratan kebutuhan ini memiliki kontribusi penting agar bisnis pemasaran sepatu online dapat melakukan aktivitasnya dengan lancar.

Untuk perancangan arsitektur perangkat lunak sistem informasi pemasaran sepatu online mengindentifikasikan semua struktur sistem, prinsip komponen (subsistem/modul), hubungannya dan bagaimana didistribusikan. Berdasarkan pemahaman dari sistem yang berjalan, maka usulan dari sistem ini juga menggunakan media sosial sebagai sarana untuk melakukan pemasaran sepatu secara online. Perancangan sistem ini dapat memberikan kemudahan bagi penguna karena dibuat dengan antarmuka yang mudah digunakan dan dapat menangani masalah pengelolaan data profil, produk yang dijual, deskripsi produk secara detil dan mekanisme pemesanan secara online, dimana data yang tersimpan dalam bentuk file yang terpusat dalam bentuk server dan kemudian diproses oleh sistem perangkat lunak.

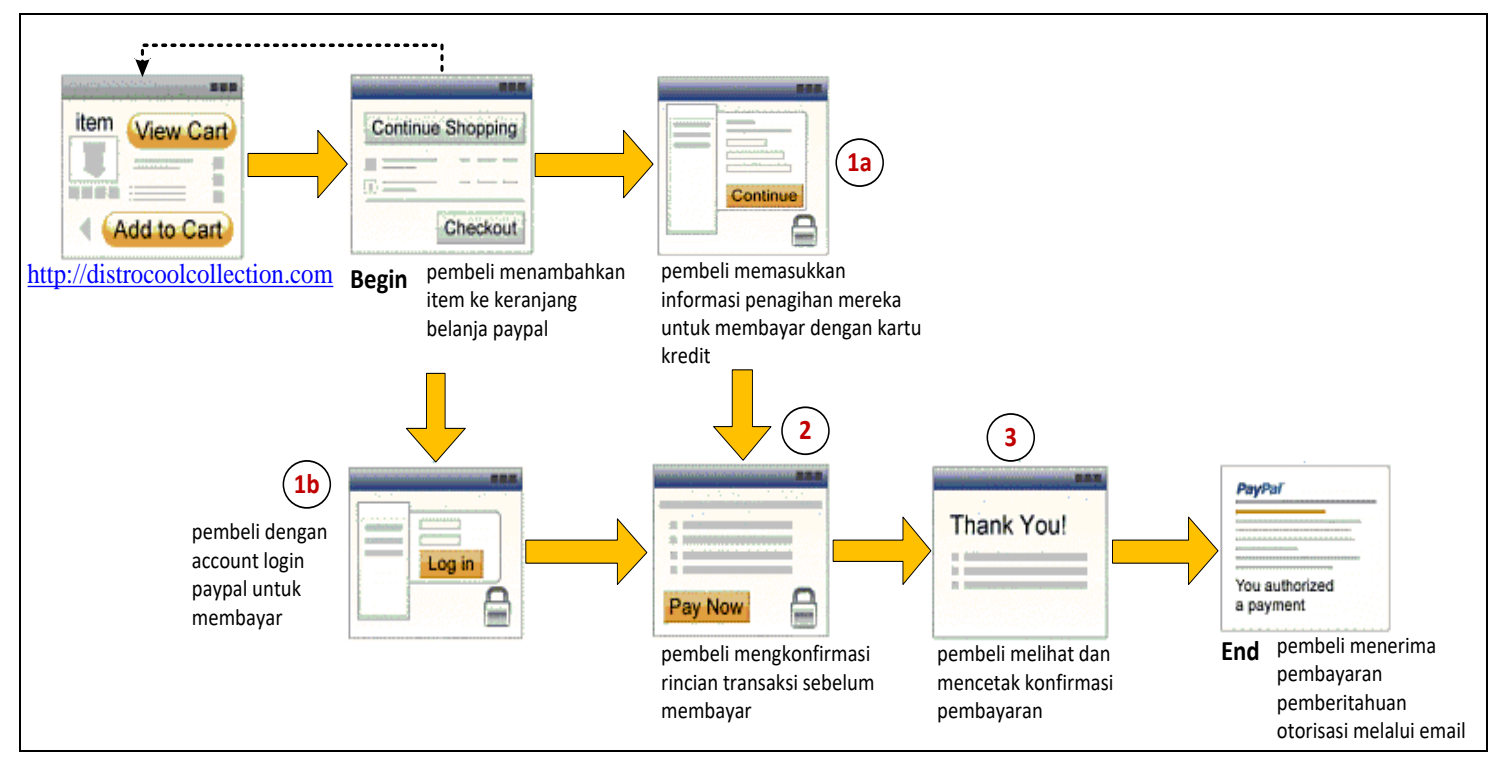

Gambar 2. Perancangan Arsitektur Sistem Informasi Pemasaran Online

Perancangan arsitektur mempresentasikan framework dari sistem perangkat lunak yang dibangun. Deskripsi arsitektur mengadopsi spesifikasi sistem, model analisis, dan interaksi subsistem yang telah didefinisikan pada tahap analisis. Adapun arsitektur sistem informasi pemasaran sepeda online yang di usulkan dapat dilihat pada gambar berikut (Gambar 2). Mekanisme ini memperlihatkan secara detil dan menyeluruh mengenai setiap alur proses bisnis dari bisnis pemasaran online. Pada gambar ini menjelaskan bahwa dalam perancangan arsitektur perangkat lunak tidak dapat dipisahkan dalam pola dimaksudkan untuk memberikan gambaran dari kebutuhan perangkat keras dan sistem jaringan dengan model dari arsitektur jaringan yang mendukung dalam penerapan pemasaran bisnis sepatu online. 


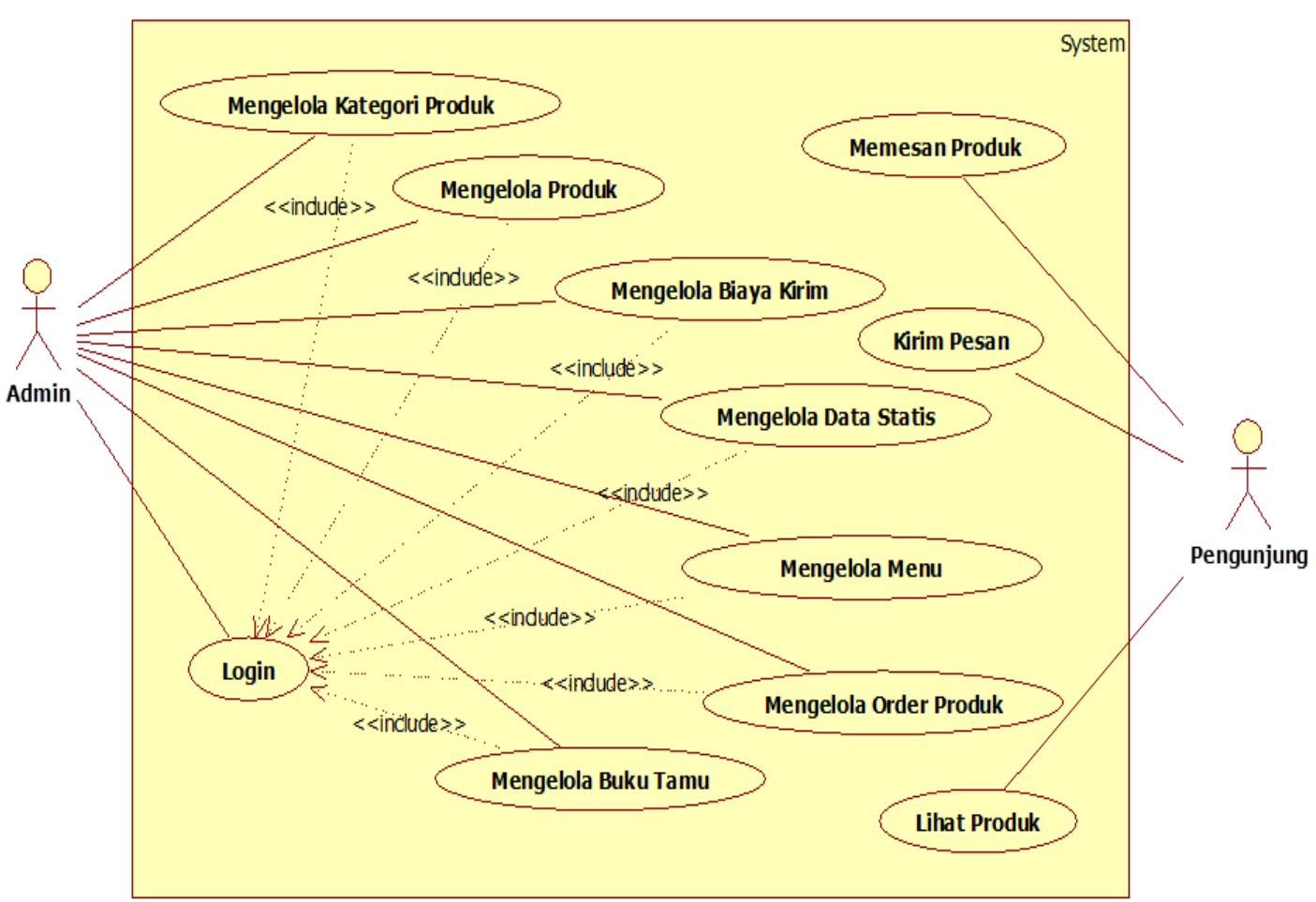

Gambar 3. Diagram Use Case Bisnis Pemasaran Sepatu Online

Pemodelan bisnis sistem informasi pemasaran sepatu online diawali dengan memperlihatkan diagram use case yang menjelaskan manfaat sistem jika dilihat menurut pandangan orang yang berada di luar sistem atau actor (pengunjung) dan admin (Gambar 3). Selanjutnya untuk menampilkan beberapa kelas serta paket-paket yang ada dalam sistem/perangkat lunak bisnis pemasaran sepatu online yang digunakan dan relasrelasi didalamnya menggunakan diagram class. Diagram class mendeskripsikan jenisjenis objek dalam sistem dan berbagai macam hubungan statis yang terdapat di antara mereka. Menunjukkan properti dan operasi sebuah class dan batasan-batasan yang terdapat dalam hubungan-hubungan objek tersebut (Gambar 4). 


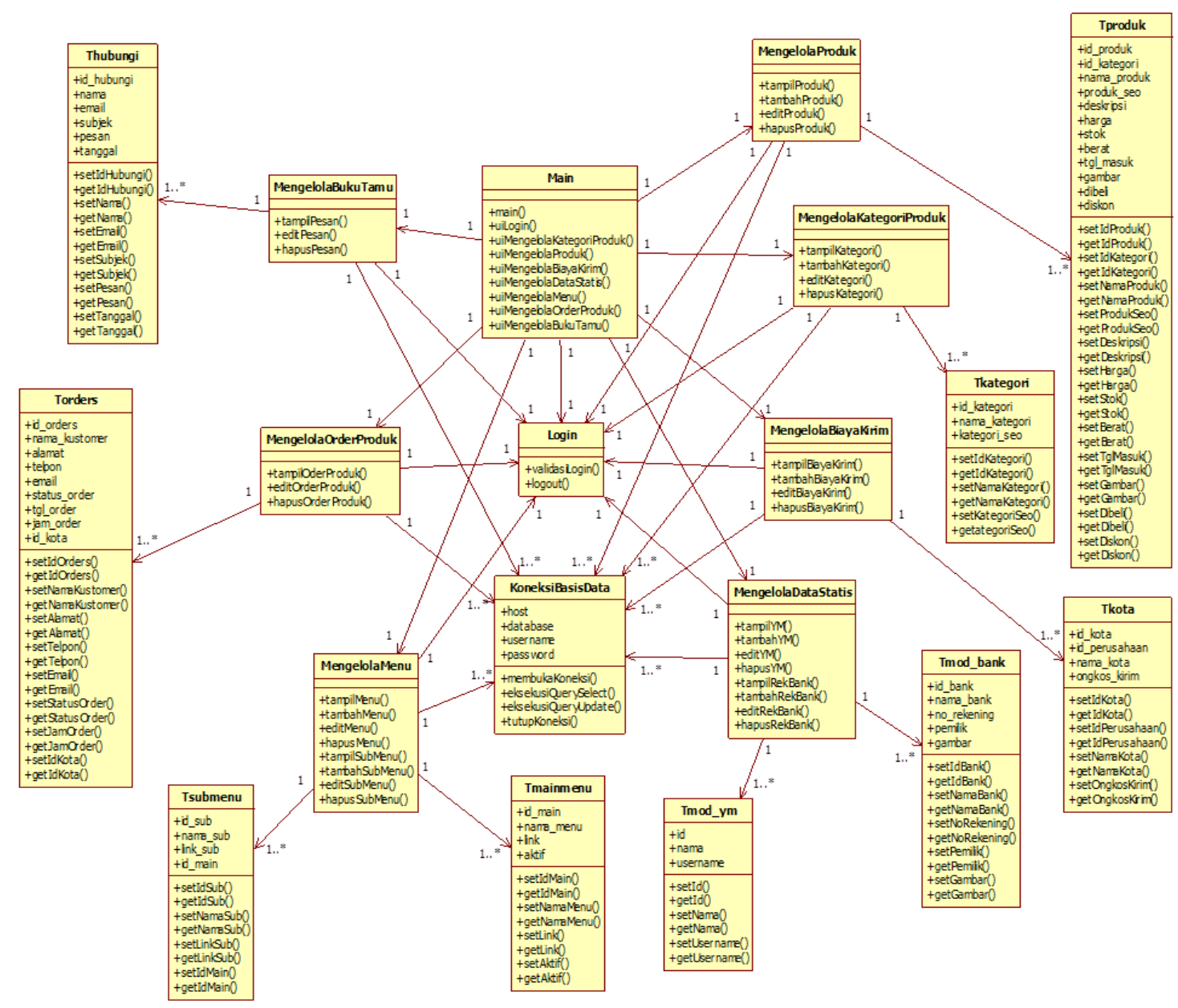

Gambar 4. Diagram Class Sistem Informasi Pemasaran Sepatu Online

Untuk memperlihatkan semua urutan proses struktur bisnis pemasaran sepatu online dapat menggunakan diagram sequence. Untuk melakukan pemesanan produk memperlihatkan interaksi antara admin dengan sistem. Proses diawali dengan melakukan login. Admin melakukan pengolahan data pesanan produk dan memvalidasinya. Selanjutnya informasi pemesanan akan disimpan ke basis data perusahaan dan menampilkan pada halaman pesanan (Gambar 5).

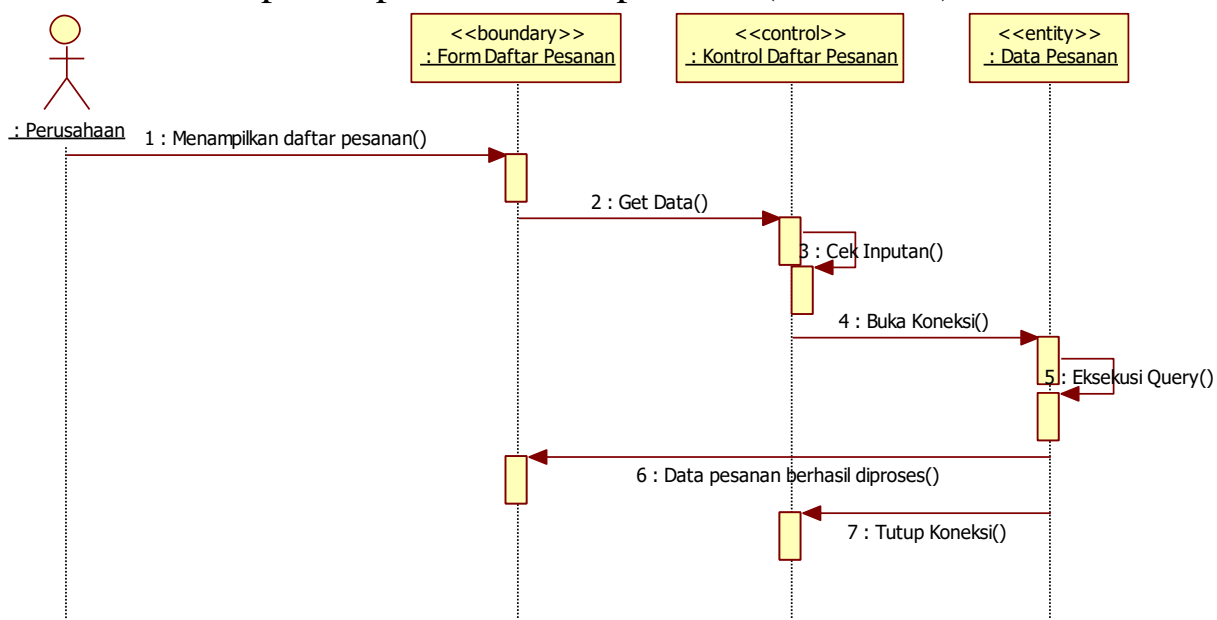

Gambar 5. Diagram Sequence Pemesanan Sepatu Online 
Untuk melakukan proses pembelian, pengunjung dapat membeli dengan hanya mengikuti langkah-langkah yang sudah ditentukan. Selanjutnya sistem mengirimkan informasi pembayaran ke email pengunjung (Gambar 6). Modul konfirmasi pembayaran merupakan proses validasi transaksi untuk semua pemesanan produk (Gambar 7). Model konfirmasi pembayaran ini sangat penting, selain untuk menjaga keabsahan data pelanggan juga dapat menginformasikan secara langsung bahwa telah terjadi transaksi penerimaan uang dalam rekening perusahaan. Konfirmasi pembayaran untuk mengerakkan fungsi validasi dalam pengiriman produk.

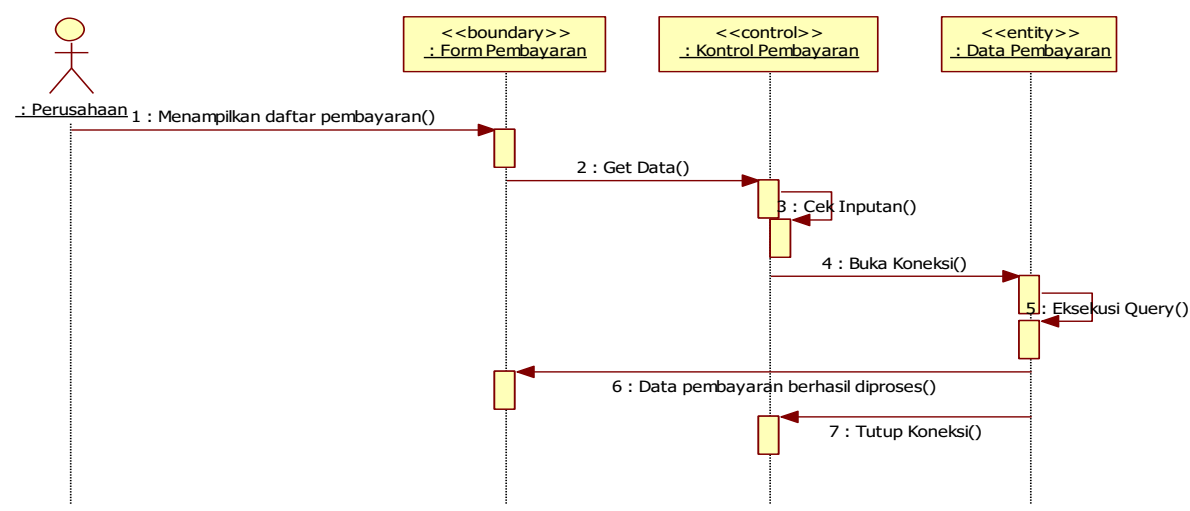

Gambar 6. Diagram Sequence Pembayaran Sepatu Online

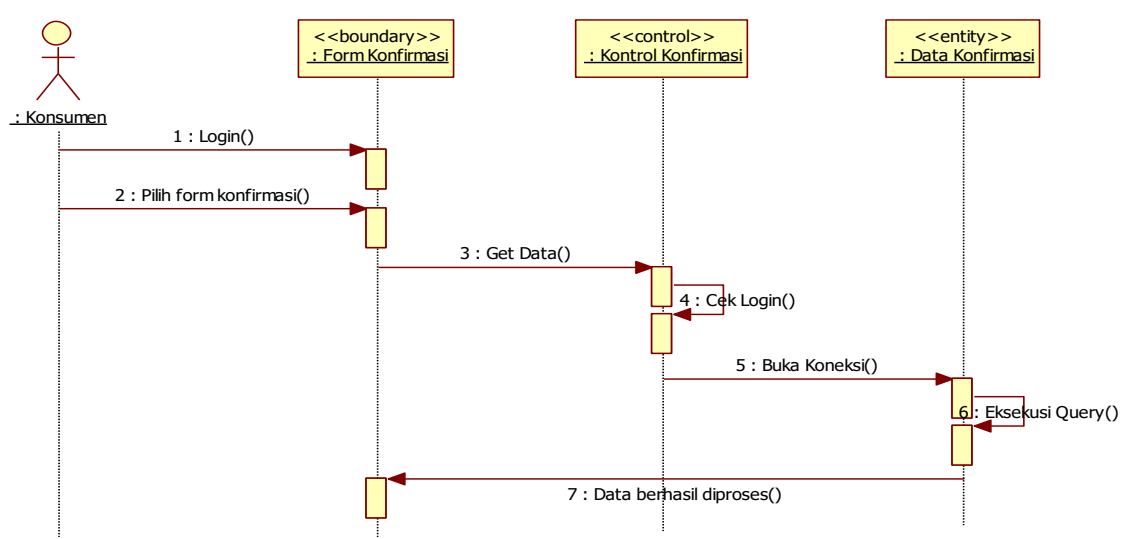

Gambar 7. Diagram Sequence Konfirmasi Pembayaran Sepatu Online

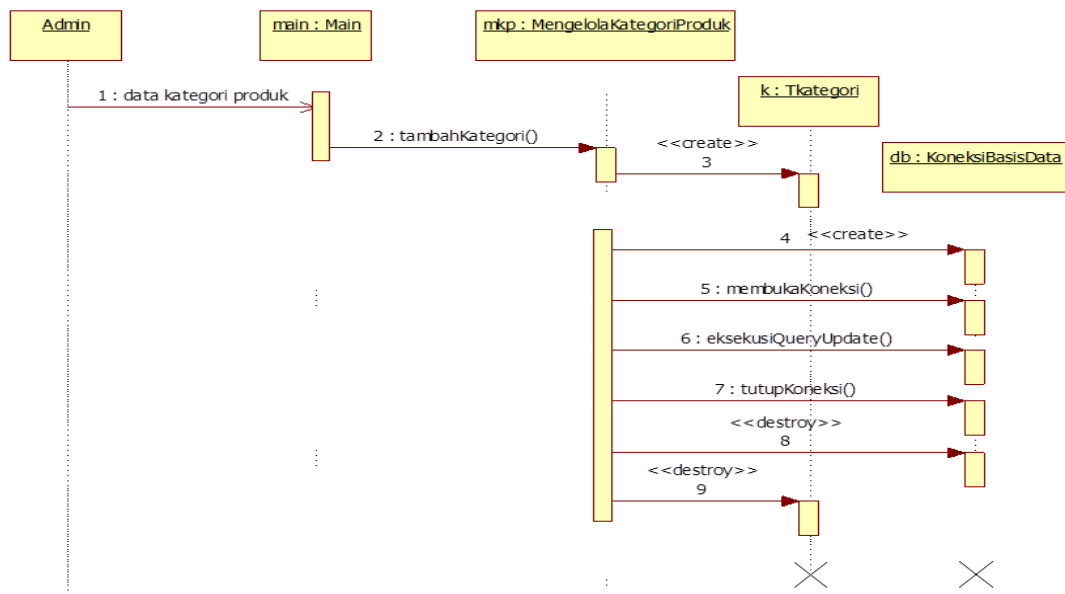

Gambar 8. Diagram Sequence Penambahan Produk Sepatu Online 
Menambah setiap kategori dan jenis produk sepatu adalah penting untuk menjaga konsistensi pelanggan atau konsumen agar semua kebutuhan mereka dapat terpenuhi dan produk sepatu selalu tersedia. Penambahan dilakukan sesuai penjadwalan dari bagian gudang berdasarkan data persediaan. Dalam mengisikan setiap penambahan data produk sepatu ada validasi sistem agar dapat menjaga kestabilan jumlah produk sepatu. Sistem memiliki informasi langsung dari setiap item produk sepatu (Gambar 8).

Berikut merupakan pembuatan halaman utama situs sistem informasi pemasaran sepatu online. Untuk halaman situs memiliki header akan menampilkan banner mengenai info diskon, promo, merek sepatu dan sebagainya yang terkini. Terdapat beberapa menu yaitu menu home yang mengarahkan pada halaman utama situs, menu kategori yang mengarahkan pada kategori produk, pembelian, transaksi, menampilkan semua produk, dan fasilitas kontak (Gambar 9).

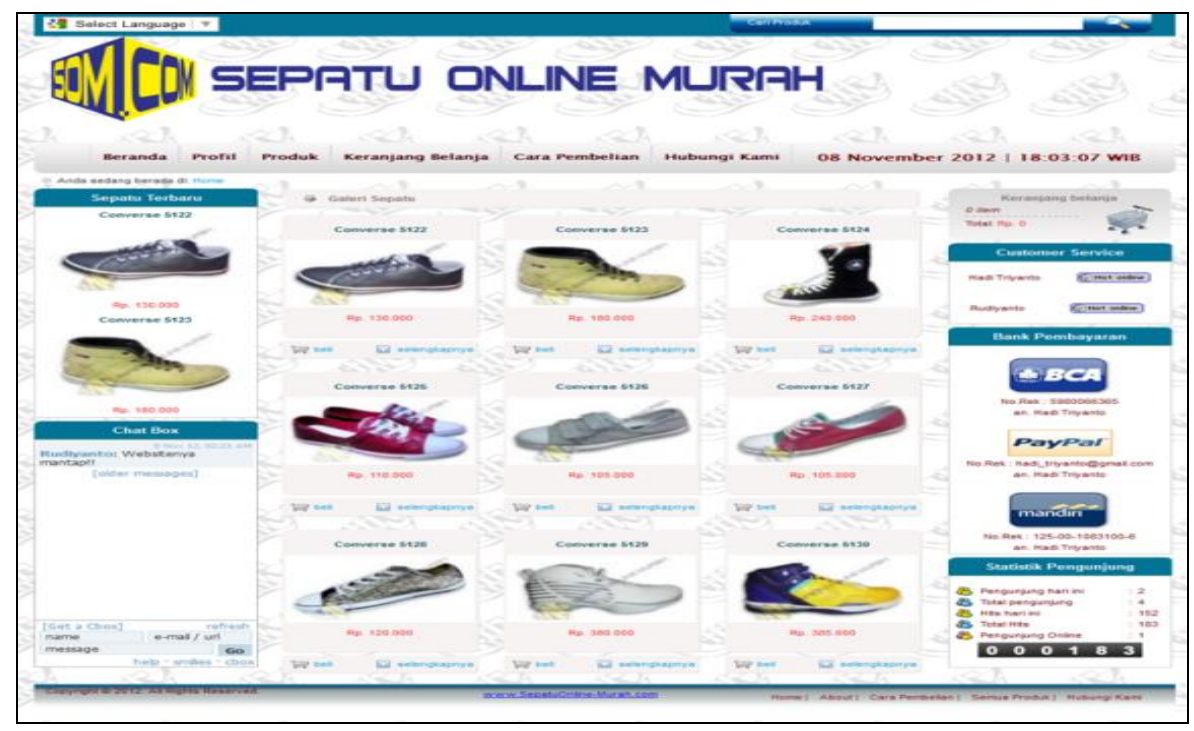

Gambar 9. Sistem Informasi Pemasaran Sepatu Online

Sistem juga memiliki halaman keranjang belanja pada halaman pengunjung. Pengunjung melakukan transaksi dan produk yang dipesan dimasukkan kedalam keranjang belanja konsumen tersebut. Pada halaman tersebut muncul data produk yang dibeli serta total pembayaran yang harus dibayar oleh konsumen (Gambar 9). 


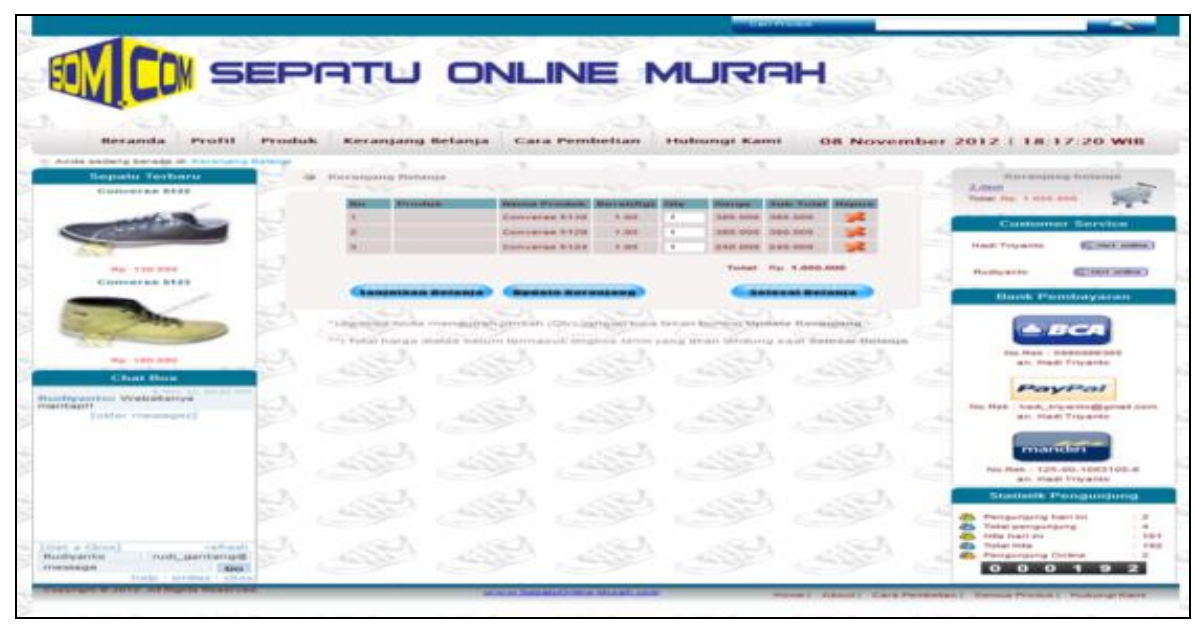

Gambar 10. Keranjang Belanja Pemasaran Online

Sistem memudahkan pelanggan dalam mencari produk-produk dalam hal ini semua merk dan tipe sepatu yang dibutuhkan dengan melalui fasilitas Cari Data Produk (Gambar 11). Pencarian ini memudahkan pelanggan atau konsumen menemukan produk dapat waktu cepat dengan sistem pencarian otomatis. Sistem pencarian ini merupakan mekanisme penting dalam merespon setiap kebutuhan pelanggan sehingga pembuatan keputusan menjadi lebih cepat.

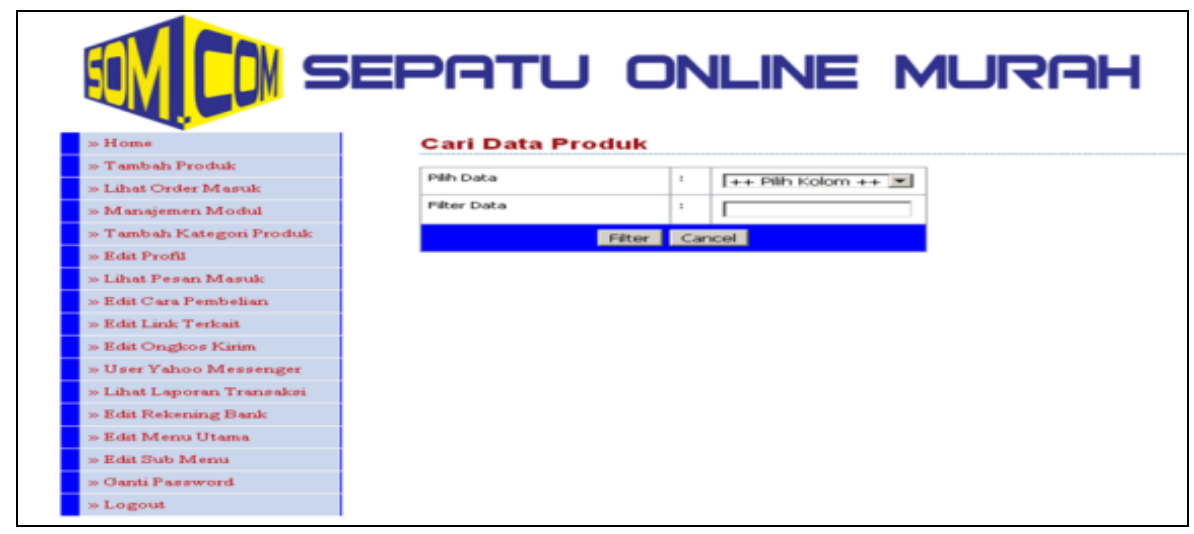

Gambar 11. Mekanisme Pencarian Sepatu Online

Sistem juga menampilkan ongkos kirim sesuai pemesanan produk dan tujuannya. Mengingat setiap daerah memiliki biaya transportasi yang berbeda. (Gambar 12). Selanjutnya sistem akan mengirimkan nomor rekening tujuan pembayaran melalui email. Apabila dalam tiga hari belum mendapatkan konfirmasi pembayaran maka pihak admin akan membatalkan pesanan dengan mengubah status pemesanannya dan membatalkan pengirimannya. Penentuan ongkos kirim disesuaikan dengan daerah pengiriman masing-masing. 


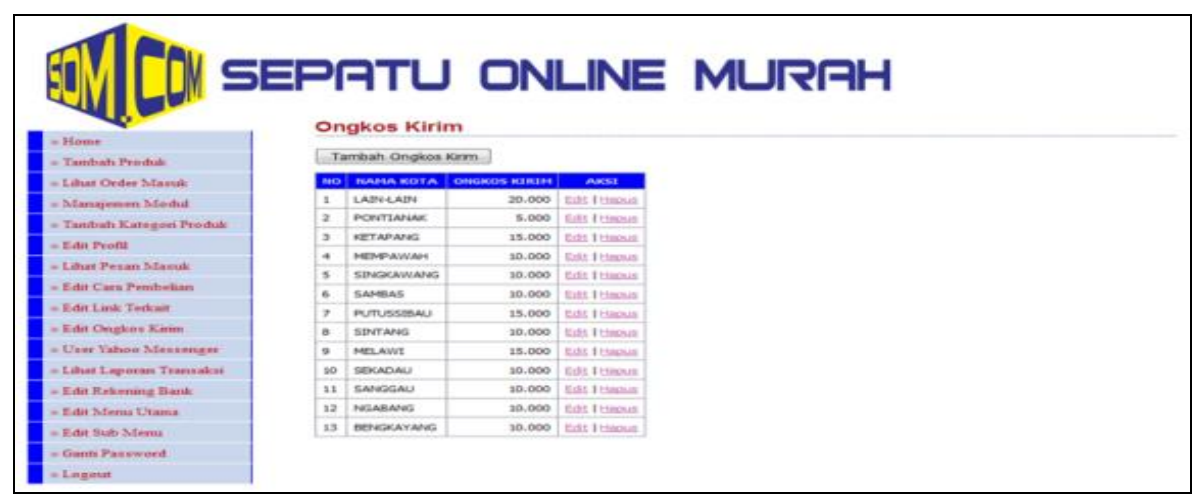

Gambar 12. Ongkos Kirim Pembelian Sepatu Online

Bisnis pemasaran online memiliki fitur navigasi dengan kemudahan bagi setiap pengunjung, dalam hal ini baik konsumen ataupun pelanggan saat mengunjungi halaman situs web. Menampilkan pesan-pesan tertentu dalam mengarahkan pengunjung, calon pembeli dapat melakukan proses pemesanan produk secara online kapanpun dan dimanapun serta mendapatkan informasi produk secara up to date. Kemampuan proses aplikasi digitisasi bisnis pemasaran online menawarkan banyak peluang dan kesempatan baru terutama kesempatan memperluas pangsa pasar dengan biaya operasional yang murah karena semua transaksi bisnis bisa berlangsung dimana saja. Semua fitur-fitur ini untuk mempermudah pelanggan dalam melakukan pembelian dan admin untuk melakukan pengelolaan semua transaksi pemasaran sepatu secara online. Sistem memiliki fasilitas notifikasi pemberitahuan melalui email setelah terjadi proses jual beli.

Implikasi dari hasil prototipe perangkat lunak sistem informasi pemasaran sepatu online dapat menjadikan kegiatan pemasaran bersifat lebih interaktif melalui penggunaan media sosial dengan sistem layanan yang lebih baik dan biaya lebih rendah. Memiliki kelebihan lebih cepat, lebih murah, komunikasi yang sangat cepat, kemudahan melalukan pengkinian konten iklan, dan memiliki cakupan dimensi pemasaran global. Strategi pemasaran digital dapat mencapai produktivitas dalam skala ekonomis dan biaya per unit menjadi rendah. Keberhasilan sistem informasi pemasaran online juga sangat bergantung kepada kesiapan infrastruktur teknologi aplikasi media sosialnya dan kemampuan menumbuhkan sifat interaktif komunikasi informasi melalui jejaring sosialnya. Ketersediaan infrastruktur dari setiap industri usaha kecil dan menengah produk sepatu adalah merupakan elemen penting dan secara fundamental sangat penting untuk menunjang kesiapan menggunakan perangkat lunak sistem informasi pemasaran online. Revolusi model bisnis dgital ini membuka peluang baru setiap organisasi untuk dapat mengakses pasar sasaran lebih luas. Kesuksesan sistem informasi pemasaran online adalah juga sangat bergantung kepada sejauhmana orientasi pasar bisnis dan kemampuan memahami sudut pandang kebutuhan dalam menjaga loyalitas pelanggan dalam kesiapannya mengadopsi inovasi teknologi media sosial.

\section{KESIMPULAN}

Hasil penelitian menghasilkan suatu perangkat lunak sistem informasi pemasaran bisnis sepatu online untuk usaha kecil dan menengah dengan sasaran utama mendukung dan memperluas area pemasaran dalam menumbuhkan pasar global. Memperkenalkan dan menjual variasi sepatu dengan ciri dan kekhususan dari segi 
artistik dan modelnya. Memiliki fitur navigasi dengan kemudahan bagi pengunjung dalam menelusuri situs web. Kesempatan membangun hubungan yang lebih personal dengan pengunjung agar dapat mempertahankan dan membangun loyalitas pelanggan secara berkelanjutan.

\section{SARAN}

Melengkapi prosedur pemasaran sepatu secara online dan meningkatkan kegiatan pengamanan untuk semua penyimpanan data pemasarannya. Melalui historis pemasaran dapat menjadikan informasi penting dalam membangun hubungan dengan pelanggan. Kegiatan ini dapat merespon lebih awal mengenai keinginan dari setiap pelanggan. Melengkapi dengan perangkat media sosial dan proses notifikasi melalui perangkat mobile untuk konfirmasi keabsahan transaksi pembayaran online.

\section{UCAPAN TERIMA KASIH}

Penulis mengucapkan terima kasih kepada pihak manajemen Sekolah Tinggi Manajemen Informatika dan Komputer (STMIK) Pontianak yang telah memberikan dukungan dalam penelitian ini. Terima kasih juga kepada rekan-rekan dosen yang telah memberikan saran dan dukungan dalam menyelesaikan penelitian ini. Kepada para reviewer saya juga mengucapkan banyak terima kasih atas bimbingan dan arahannya untuk perbaikan penelitian ini sehingga menjadi lebih baik lagi.

\section{DAFTAR PUSTAKA}

[1] Anwar, N., \& Daniel, E., 2015, Marketing in Online Businesses: The Case of Migrant Entrepreneurial Businesses in The UK, UK Academy for Information Systems, hal 1-31.

[2] Roma'n, S., 2010, Relational Consequences of Perceived Deception in Online Shopping: The Moderating Roles of Type of Product, Consumer's Attitude Toward the Internet Consumer's Demographics, Journal of Business Ethics, 95(3), hal 373-391.

[3] Mohammadpour, A., Arbatani, T. R., Gholipour, T. H., Farzianpour, F., \& Hosseini, S., 2014, A Survey of The Effect of Social Media Marketing on Online Shopping of Customers by Mediating Variables, Journal of Service Science and Management, 7(05), hal 368-376.

[4] Ahmed, B., Maâti, M. B., \& Al Mohajir, B., 2014, The Intelligence of E-CRM Applications and Approaches on Online Shopping Industry, International Journal of Innovation and Scientific Research, 12(1), hal 213-216.

[5] Yang, X., \& Luo, J., 2009, Development of Online Marketing Information System for Wood Products, International Conference on E-Business and Information System Security, 2009, IEEE, hal 1-3.

[6] Ghasemaghaei, M., \& Hassanein, K., 2015, Impact of Persuasion Processes on Consumer Attitude Towards Online Shopping: The Moderating Role of Product Involvement and Consumer Self-Efficacy, Twenty-first Americas Conference on Information Systems, hal $1-7$.

[7] Holliman, G., \& Rowley, J., 2014, Business to Business Digital Content Marketing: Marketers' Perceptions of Best Practice, Journal of research in interactive marketing, 8(4), hal 269-293.

[8] Berthon, P. R., Pitt, L. F., Plangger, K., \& Shapiro, D., 2012, Marketing Meets Web 2.0, Social Media, and Creative Consumers: Implications for International Marketing Strategy, Business Horizons, Elsevier, 55, hal 261-271. 
[9] Kietzmann, J. H., Hermkens, K., \& McCarthy, I. P., Silvestre, B. S., 2011, Social Media? Get Serious! Understanding the Functional Building Blocks of Social Media, Business Horizons, Elsevier, 54 hal 241-251.

[10] Bughin, J., \& Chui, M., 2013, Evolution Of The Networked Enterprise: McKinsey Global Survey Results, McKinsey Quarterly, hal 1-10.

[11] Hwang, D., 2012, A Comprehensive Framework for Online Store Functionalities, Issues in Information Systems, 13(2), hal 336-345.

[12] Liang, T. P., \& Lai, H. J., 2000, Electronic Store Design and Consumer Choice: An Empirical Study, International Conference on System Sciences, IEEE, hal 1-10.

[13] Almousa, M., 2013, Barriers to E-Commerce Adoption: Consumers' Perspectives from a Developing Country, iBusiness, 5, hal 65-71.

[14] Setiawan, R., \& Achyar, A., 2012, Effects of Perceived Trust and Perceived Price on Customers' Intention to Buy in Online Store in Indonesia, ASEAN Marketing Journal, hal 26-36.

[15] Cho, V., \& Lau, C., 2014, An Integrative Framework for Customizations on Satisfaction: The Case of an Online Jewelry Business in China, Journal of Service Science and Management, 7, hal 165-181.

[16] Constantinides, E., 2014, Foundations of Social Media Marketing, Procedia-Social and behavioral sciences, hal 148, 40-57.

[17] Laudon, K. C., Traver, C. G., 2013, E-Commerce 2014: Business, Technology, Society, Tenth Edition, Prentice-Hall, Inc.

[18] Creswell, J. W., 2014, Research Design: Qualitative, Quantitative, and Mixed Methods Approaches (Fourth Edition ed.), California: SAGE Publications, Inc.

[19] Sommerville, Ian., 2016. Software Engineering, Tenth Edition, Pearson Education Limited. 